Michael Joannidis

Christian J. Wiedermann

\section{Radiocontrast-induced acute kidney injury in the ICU: worse than presumed?}

Received: 3 August 2011

Accepted: 4 August 2011

Published online: 3 November 2011

(C) Copyright jointly held by Springer and ESICM 2011

This editorial refers to the article available at:

doi:10.1007/s00134-011-2389-8.

M. Joannidis ( $)$

Medical Intensive Care Unit, Department of Internal Medicine I, Medical University Innsbruck, Anichstrasse 35,

6020 Innsbruck, Austria

e-mail: michael.joannidis@i-med.ac.at

C. J. Wiedermann

Division of Internal Medicine,

Central Hospital of Bolzano, Bolzano, Italy

Contrast agents are administered to millions of patients annually worldwide [1]. Contrast-induced acute kidney injury (CI-AKI) is one of the most common complications of the use of iodinated contrast media. It accounts for up to $11 \%$ of hospital-acquired renal failures [2]. Reported incidences range from well below $2 \%$ in unselected collectives of patients [3] up to nearly $7 \%$ in patients with chronic kidney disease (CKD) and an estimated glomerular filtration rate (eGFR) $<60 \mathrm{ml} / \mathrm{min} / 1.73 \mathrm{~m}^{2}[4,5]$.

CI-AKI is associated with increased morbidity and mortality and does have significant implications for health care costs due to extended length of stay (LOS) in hospital and additional treatment requirements [5]. Pathophysiological features of this condition consist of transitory renal vasoconstriction and renal ischemia, especially in the renal outer medulla where oxygen levels are at a critical level, combined with direct tubular epithelial toxicity. CI-AKI has been defined in different ways, but an increase in serum creatinine $\geq 0.5 \mathrm{mg} / \mathrm{dl}$ or $\geq 25 \%$ within $48-72 \mathrm{~h}$ after contrast application is the most widely used criterion $[5,6]$.

CI-AKI rarely develops in patients with normal renal function, but several risk factors have been described. Decreased baseline renal function, heart failure, diabetes, dehydration, hypotension, older age, and the type and amount of contrast volume applied have been shown to have the greatest impact $[5,7]$. The type of investigation may also influence the risk of developing CI-AKI with noncoronary angiography and coronary angiography/percutaneous coronary intervention possibly carrying the greatest risk [8]. The use of low-osmolar and iso-osmolar contrast agents and limiting the amount of administered contrast media as well as mild volume expansion with isotonic crystalloids are well established procedures for prevention [5, 9, 10]. All this knowledge, however, is mainly derived from non-critically ill patients undergoing CT scans, cardiac catheterization, or cardiovascular surgery. Very little is known about the risk factors and longterm outcome of CI-AKI in critically ill patients.

The study by Hoste et al. [11] published in the current issue of Intensive Care Medicine investigates a large cohort of 787 critically ill, primarily surgical (76.2\%) patients receiving intravenous or intraarterial contrast media for CT scans or noncoronary angiography. Only iodinated nonionic, low-osmolar or iso-osmolar contrast media were applied. Using "conventional" criteria [6], CI-AKI was observed in 128 patients (16.3\%), of whom about one-quarter progressed to AKI stage 3, and 14 patients $(11 \%)$ required renal replacement therapy (RRT). CI-AKI also resulted in significantly increased LOS as well as both ICU and 1-year mortality. Applying the more sensitive KDIGO criteria, 175 patients $(22 \%)$ were classified as CI-AKI with comparable to worse outcome in terms of RRT requirement or mortality. Multiple logistic regression analysis revealed increased serum creatinine as a reflection of reduced GFR, diuretic therapy, use of 
vasopressors, and hypotension as independent risk factors for developing CI-AKI. No influence of the type of investigation, CT scan versus angiography, could be demonstrated.

This study, currently the largest one investigating CI-AKI in critically ill patients, makes a highly valuable and timely contribution to our knowledge of an iatrogenic complication of the routine diagnostic procedure of contrast agent administration. Despite its retrospective design, the study sheds light on several important aspects of CI-AKI. First of all, the incidence of CI-AKI in the range of 16-22\% appeared to be much higher in critically ill patients than that described in other patient groups [5]. In conjunction with this, the requirement of RRT and a 1-year mortality of roughly $56 \%$ in patients suffering from CI-AKI were much higher than expected from previous trials in non-critically ill patients $[12,13]$. When considering only the critically ill, mortality rates appeared roughly three times higher in patients developing CI-AKI in the study by Hoste et al. [11], which demonstrates the possibility that CI-AKI worsens severe and life-threatening conditions in critically ill patients.

The predominant risk factors for this specific group of patients were represented mainly by impaired baseline renal function and reduced renal perfusion. Diuretics turned out to be a further independent hazard for developing CI-AKI. Although use of diuretics might be interpreted simply as a therapeutic consequence of heart failure, previous prospective trials demonstrated that (loop) diuretics significantly enhance the incidence of AKI if given at the time of contrast application [14, 15]. Female sex, however-previously reported as risk factor for CI-AKI [16, 17] — was not found to be associated with a higher rate of AKI in the present study [11].

Preventive hydration procedures including volume expansion with normal saline and sodium bicarbonate as well as $\mathrm{N}$-acetyl-cysteine (NAC) were carried out in patients with reduced baseline renal function in a nonstandardized way, which may be considered a major limitation of the study by Hoste et al. [11]. Despite implementation of such procedures a large number of patients developed CI-AKI and a few progressed to more severe stages of the disease. This, however, does not necessarily mean that conventional preventive measures are useless: in this study, they were probably implemented in patients who were identified as carrying a higher risk for developing AKI. However, the measures appeared to be inadequate. It is possible that in this study of critically ill patients, use of conventional criteria for both patient selection and type and/or intensity of preventive interventions may have led to missing other important risk factors whose identification might have helped to optimize implementation of more effective measures to prevent CI-AKI.

What are the consequences of this study for our daily clinical practices? First of all, it becomes obvious that the critically ill are a group of patients who are clearly at high risk for developing CI-AKI. Even more, CI-AKI poses a significant hazard to this population in terms of increased requirements for RRT as well as increased LOS and higher mortality rates.

Secondly, in addition to the well known risk factors for CI-AKI such as chronic renal disease, diabetes, and heart failure, reduced renal perfusion characterized by decreased mean arterial pressure as well as use of vasopressors to treat hypotension in the ICU setting likely represents a predominant risk factor. Third, as already shown previously, periprocedural application of (loop) diuretics increases the risk for CI-AKI and should be avoided. Obviously discontinuation of any other nephrotoxic drug (e.g., aminoglycosides, NSAIDS) is highly warranted [10].

This leads us to the important issue of prevention. Although no clear benefit of any preventive measure could be demonstrated in this study by Hoste et al. [11], it may be concluded from the data presented that renal perfusion must be optimized before administering radiocontrast agents. According to currently available data this should preferably be achieved by periprocedural volume expansion using either normal saline or isotonic sodium bicarbonate [10]. Fast prehydration protocols with isotonic bicarbonate have been shown to be beneficial for emergent procedures in some studies [18-20]. Which crystalloid to use and how to ideally perform volume expansion in critically ill patients, however, are questions that can only be reliably answered by a large prospective randomized trial.

\section{References}

1. Horl WH (2009) Contrast induced nephropathy. Wien Klin Wochenschr 121:15-32

2. Nash K, Hafeez A, Hou S (2002) Hospital-acquired renal insufficiency. Am J Kidney Dis 39:930-936
3. Bartholomew BA, Harjai KJ, Dukkipati S, Boura JA, Yerkey MW, Glazier S, Grines CL, O'Neill WW (2004) Impact of nephropathy after percutaneous coronary intervention and a method for risk stratification. Am J Cardiol 93:1515-1519
4. Weisbord SD, Mor MK, Resnick AL, Hartwig KC, Palevsky PM, Fine MJ (2008) Incidence and outcomes of contrast-induced AKI following computed tomography. Clin J Am Soc Nephrol 3:1274-1281 
5. McCullough PA (2008) Contrastinduced acute kidney injury. J Am Coll Cardiol 51:1419-1428

6. Thomsen HS, Morcos SK (2003) Contrast media and the kidney: European Society of Urogenital Radiology (ESUR) guidelines. Br J Radiol 76:513-518

7. Mehran R, Aymong ED, Nikolsky E, Lasic Z, Iakovou I, Fahy M, Mintz GS, Lansky AJ, Moses JW, Stone GW, Leon MB, Dangas G (2004) A simple risk score for prediction of contrastinduced nephropathy after percutaneous coronary intervention: development and initial validation. J Am Coll Cardiol 44:1393-1399

8. Weisbord SD, Mor MK, Resnick AL, Hartwig KC, Sonel AF, Fine MJ, Palevsky PM (2008) Prevention, incidence, and outcomes of contrastinduced acute kidney injury. Arch Intern Med 168:1325-1332

9. Brown JR, Robb JF, Block CA, Schoolwerth AC, Kaplan AV, O'Connor GT, Solomon RJ, Malenka DJ (2010) Does safe dosing of iodinated contrast prevent contrast-induced acute kidney injury? Circ Cardiovasc Interv 3:346-350

10. Joannidis M, Druml W, Forni LG, Groeneveld AB, Honore P, Oudemansvan Straaten HM, Ronco C, Schetz MR, Woittiez AJ (2010) Prevention of acute kidney injury and protection of renal function in the intensive care unit. Expert opinion of the Working Group for Nephrology, ESICM. Intensive Care Med 36:392-411
11. Hoste EA, Severine D, De Waele JJ, Delrue L, Defreyne L, Benoit D, Decruyeanaere J (2011) Epidemiology of contrast-associated acute kidney injury in ICU patients: a retrospective cohort analysis. Intensive Care Med. doi:10.1007/s00134-011-2389-8

12. Joannidis M, Schmid M, Wiedermann CJ (2008) Prevention of contrast mediainduced nephropathy by isotonic sodium bicarbonate: a meta-analysis. Wien Klin Wochenschr 120:742-748

13. Solomon RJ, Mehran R, Natarajan MK, Doucet S, Katholi RE, Staniloae CS, Sharma SK, Labinaz M, Gelormini JL, Barrett BJ (2009) Contrast-induced nephropathy and long-term adverse events: cause and effect? Clin J Am Soc Nephrol 4:1162-1169

14. Solomon R, Werner C, Mann D, D'Elia J, Silva P (1994) Effects of saline, mannitol, and furosemide to prevent acute decreases in renal function induced by radiocontrast agents. N Engl J Med 331:1416-1420

15. Majumdar SR, Kjellstrand CM, Tymchak WJ, Hervas-Malo M, Taylor DA, Teo KK (2009) Forced euvolemic diuresis with mannitol and furosemide for prevention of contrast-induced nephropathy in patients with CKD undergoing coronary angiography: a randomized controlled trial. Am J Kidney Dis 54:602-609

16. Mueller C, Buerkle G, Buettner HJ, Petersen J, Perruchoud AP, Eriksson U, Marsch S, Roskamm H (2002) Prevention of contrast media-associated nephropathy: randomized comparison of 2 hydration regimens in 1620 patients undergoing coronary angioplasty. Arch Intern Med 162:329-336
17. Jackson EA, Moscucci M, Smith DE, Share D, Dixon S, Greenbaum A, Grossman PM, Gurm HS (2011) The association of sex with outcomes among patients undergoing primary percutaneous coronary intervention for ST elevation myocardial infarction in the contemporary era: insights from the Blue Cross Blue Shield of Michigan Cardiovascular Consortium (BMC2). Am Heart J 161:106-112

18. Merten GJ, Burgess WP, Gray LV, Holleman JH, Roush TS, Kowalchuk GJ, Bersin RM, Van MA, Simonton CA III, Rittase RA, Norton HJ, Kennedy TP (2004) Prevention of contrast-induced nephropathy with sodium bicarbonate: a randomized controlled trial. JAMA 291:2328-2334

19. Wiedermann CJ, Joannidis M (2010) Increasing evidence base for sodium bicarbonate therapy to prevent contrast media-induced acute kidney injury: little role of unpublished studies. Nephrol Dial Transplant 25:650-654

20. Recio-Mayoral A, Chaparro M, Prado B, Cozar R, Mendez I, Banerjee D, Kaski JC, Cubero J, Cruz JM (2007) The reno-protective effect of hydration with sodium bicarbonate plus $\mathrm{N}$-acetylcysteine in patients undergoing emergency percutaneous coronary intervention: the RENO Study. J Am Coll Cardiol 49:1283-1288 